\title{
Rehabilitation of an Edified Building in a Seismic Zone in Algeria According to the Eurocode 8-3
}

\author{
Amar Kassoul", Abdelkader Zerrouk, Imane Djafar Henni \\ Laboratory of Structures, Geotechnics and Risks (LSGR), Hassiba Benbouali University of Chlef, Algeria
}

Copyright $\bigcirc 2018$ by authors, all rights reserved. Authors agree that this article remains permanently open access under the terms of the Creative Commons Attribution License 4.0 International License

\begin{abstract}
The objective of this paper is to perform a study on rehabilitation of a vital seven-story administrative building located in a low seismic area according to the old Algerian earthquake regulations (RPA88). Modifications were brought to the old code, including the seismic zoning which passed from moderate to high seismicity. The applied rehabilitation standards are based on the recommendations of the Eurocode 8-3 (EC8-3). The assessment of the vulnerability of the existing construction showed that the seismic forces at the base are lower than those required by the Algerian seismic code RPA99/V2003. As a retrofitting measure to strengthen this construction, the addition of new shears walls in both directions of the building was proposed. The dynamic study of the structure with the suggested structural intervention fulfilled all the required dynamic characteristics. For setting evidence of the performance of the proposed strengthening solution for the existing construction, a non-linear static analysis or pushover was accomplished. The obtained results using the SAP 2000 software enable us to make a comparison between the nonlinear behavior of the modified structure and the initial one. Compared to the original structure, from the point of view of the performance status, the strengthened structure showed a marked improvement in the strength and damping exceeding $80 \%$ while the overall capacity for resistance is enhanced more than three times.
\end{abstract}

Keywords Rehabilitation, Building, Eurocode 8-3, Retrofitting, Strengthening

\section{Introduction}

Many reinforced concrete constructions yet in service in Algeria, especially those built before the enactment of the governing seismic code in 2003[1], were originally designed to support only gravity loads lacking the needed stiffness to deal with even a moderate seismic event. According to the current earthquake standards old reinforced concrete structures were designed and built without essential seismic details deemed vital to withstand large lateral loads. These old buildings could cease their serviceability and seriously jeopardize the safety of occupants because of the influence of complex interacting phenomena such as shear deficient columns which are the most critical elements present substandard shear design to inhibit shear failure, improper splicing of longitudinal reinforcement bars (insufficient lap length, and/or improper lap location), structural system consists of weak columns and strong beams, and finally unsafe design and detailing within the joint region beam-column connection nodes with less shear stress capacity [1].

Usually earthquakes induce damaging lateral forces but may become more deteriorating because of ignorance or lack of effective and integrated rehabilitation. Indeed, precipitated or incorrect design and poor enforcement of building work can lead to widespread damage and even large casualties during future earthquakes. Therefore, the need to disseminate knowledge to engineers regarding the repair of concrete is essential, namely reasonable design, repair or enhancement which includes the assessment of structural and modern knowledge of repair and strengthening techniques and appropriate method of implementing the structural rehabilitation [2].

Many researches were carried out in this area. Sarno et al. [3] have studied a seismic assessment of a reinforced concrete school building retrofitted with innovative braces. The existing frame was retrofitted through innovative buckling restrained braces (BRBs). The seismic performance of the as-built and consolidated structure was investigated through refined static and dynamic analyses, both linear and nonlinear. The nonlinear static analyses demonstrated that the use of BRBs is very efficient to enhance the global over-strength (about 30\%) and energy dissipation capacity of the reinforced concrete frame under moderate-to-high magnitude earthquakes.

Hassaballa et al. [4] have conducted a seismic evaluation and retrofitting of existing Hospital building in Sudan. The building was constructed according to the design using one case of loads, this situation needs remedy. This paper suggested two solutions for this problem based on 
strengthening the weak columns by inserting reinforced concrete shear walls. It was found that solution one solved the problem partially because some columns were still unsafe, but solution two solved the problem completely and all columns were safe. Ahmed et al. [5] have guided a study on the performance and strengthening of non-seismically designed concrete framed structure building under seismic loading conforming to Kingdom of Saudi Arabia's Code. A shear wall coupled structure system is adopted as seismic strengthening option as the structure of building is found unsafe under the seismic loading. The seismic load and other loadings are adopted as conforming to ACI Code. The shear wall structure analysis results are compared with the complete frame structure building. It was found that the provision of shear wall is an appropriate strengthening technique for the building under seismic loading. Knowing that, there are other works on the rehabilitation of vulnerable structures, namely that of Davidovici $[6,7]$ on the rehabilitation of existing hospitals and schools as well as their strengthening with reinforced concrete walls. In Algeria, as in other seismic countries, several practical studies have been conducted on the rehabilitation of structures after each earthquake. Two experiences in rehabilitation made after the earthquakes of El Asnam 1980 and Boumerdes 2003 are worthy to be cited. In Algeria, despite the existence of recommendations [8] and a technical guide of repair or strengthening methods for structures [9], there is a lack of regulatory support for the study of rehabilitation. It is well known that the measures used to achieve ductility and toughness in structural elements is unique to each construction material and to each type of structural system for each building.

The purpose of this study is to present first, a summary of the rehabilitation method of Eurocode 8-3 [10]. Then we apply the measures indicated in the latter code by proportioning the structure adequately to rehabilitate an office building in Algeria, which was edified in low seismicity zone (zone I) according to the pre-amended Algerian Earthquake Regulations (RPA88) [12]. The amendments to Regulation in 2003 resulted in the production of a new regulatory seismic zoning and the zone was switched at medium scale zone IIa. Finally, the paper highlights the performance of the proposed solution for the strengthening using a nonlinear static analysis.

\section{Method of Method of Rehabilitation According to the Eurocode 8-3}

\subsection{Information for Structural Assessment}

According to the steps described by Eurocode 8-3 [10], the first step governing the structural rehabilitation begins with the collection of the general and historical information of the building, especially the required input data to begin the methodology rehabilitation.

\subsubsection{General Information and History}

In order to assess the earthquake resistance of existing structures, the input data shall be collected from a variety of sources, including:

- Available documentation specific to the building in question,

- Relevant generic data sources (e.g. contemporary codes and standards),

- Field investigations and, in most cases, in-situ and/or laboratory measurements and tests, as described in the following steps.

It should check between the data collected from different sources to minimize uncertainties.

\subsubsection{Required Input data}

The minimum input data required for the evaluation of the structure according to Eurocode 8-3 [10] are summarized as follow:

a. Identification of the structural system and its compliance with the regularity criteria in EC8-1 [11]. The information should be collected either from onsite investigation or from original design drawings, if available. In this latter case, information on possible structural changes since construction should also be collected.

b. Identification of the type of building foundations.

c. Identification of the ground conditions as categorized in EC8-1 [11].

d. Information about the overall dimensions and cross-sectional properties of the building elements and the mechanical properties and condition of constituent materials.

e. Information about identifiable material defects and inadequate detailing.

f. Information on the seismic design criteria used for the initial design, including the value of the force reduction factor (q-factor), if applicable.

g. Description of the present and/or the planned use of the building (with identification of its importance category, as described in EC8-1 [11].

h. Re-assessment of imposed actions taking into account the use of the building.

i. Information about the type and extent of previous and present structural damage, if any, including earlier repair measures.

The different types of analysis and different values of the confidence coefficients must be adopted according to the volume and quality of the gathered information.

\subsection{Definition and Identification of Knowledge Levels}

The type of allowable analysis and the appropriate confidence factor values, according EC8-3 [10] is based on three knowledge levels, namely limited knowledge (KL1), normal (KL2) and full (KL3). The factors 
determining the appropriate knowledge level are:

- The geometry of the structural system and non-structural elements,

- Detailing of reinforcement in reinforced concrete and,

- The mechanical properties of the constituent materials.

The identification of the knowledge level of these factors is necessary to examine the following aspects:

i. Physical condition of reinforced concrete elements and presence of any degradation, due to carbonation, steel corrosion, etc.

ii. Continuity of load paths between lateral resisting elements.

\subsection{Confidence Factors}

To determine the properties of existing materials used in the calculation of capacity, and when this one must is to be compared with demand for safety verification, the average values obtained from in-situ tests and from the additional sources of information shall be divided by the coefficient of confidence, CF, given by the EC8-3 [10], which is the appropriate knowledge level that complies with the requirements. However, in order to compute the force capacity in terms of the ductile components, intended to be used in the safety check, the mean value properties of existing materials shall be multiplied by the confidence factor $\mathrm{CF}$ for the appropriate knowledge level.

\subsection{Vulnerability Assessment}

Assessment is a quantitative procedure for checking whether an existing undamaged or damaged building will satisfy the required limit state appropriate to the seismic action under consideration, as specified in EC8-1 [11].

\section{Description of Building}

From original outline construction built drawings as a source of information the evaluation of the structure can be derived.

\subsection{General Information and History of the Existing Building}

The basic documentation available of the structure is original design specifications of the structural components shown in Fig. 1 and Table 1. The relevant sources of generic data are reached based on Algerian Earthquake Regulations RPA88 [12] and the French Concrete Code CCBA 68 [13] used at the time. Regarding inexistent field investigations, but currently the foundation of the built structure is loose ground soil.

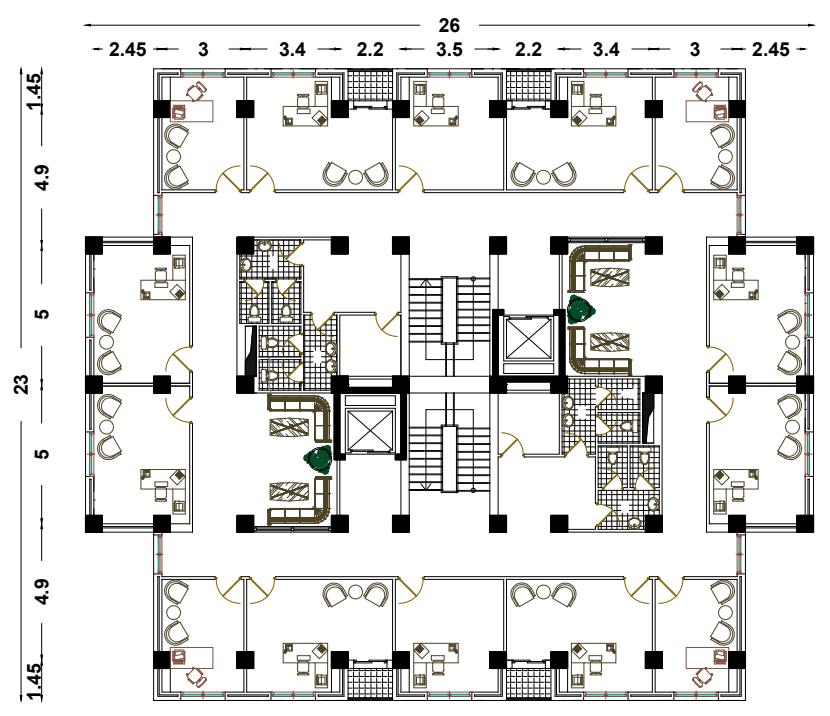

Figure 1. Plan of old building

Table 1. Sizes of beams and Columns

\begin{tabular}{|c|c|c|}
\hline Components & Storey & Sizes $(\mathrm{cm} \times \mathrm{cm})$ \\
\hline \multirow{2}{*}{ Columns } & $1,2,3,4$ & $40 \times 40$ \\
\cline { 2 - 3 } & $4,5,6,7$ & $35 \times 35$ \\
\hline \multirow{2}{*}{ Beams } & Primary & $30 \times 40$ \\
\cline { 2 - 3 } & Secondary & $30 \times 35$ \\
\hline
\end{tabular}

\subsection{Necessary Input Data of the Existing Building}

The necessary input data for the structure assessment according to Eurocode 8-3 [10] are:

a. The classification and identification of the structural system 1 and of its compliance with the regularity criteria according to Algerian Earthquake Regulations RPA99/V2003 [1], are:

- The administrative building is of vital importance of usage classified in group III.

- Its structural system is composed by resisting frames,

- The arrangement of these structural elements largely meets the criteria of regularity in code RPA99 / V2003 [1].

b. The existing foundations of the structure are strip footing

c. The soil is defined as loose soil (S3);

d. The value of the behavior factor (q factor) used in the initial design is equal to 4 .

To select the type of permissible analysis and the appropriate values of the confidence factors, according to EC 8-3 [10], the established knowledge level is Level 2 corresponds to the normal knowledge (KL2). 


\subsection{Identification of Geometry, Details and Materials}

\subsubsection{Geometry}

The bracing system in both directions is provided by the resisting frames systems. The direction of floor slabs considered as rigid diaphragm and the various quotes between axes are illustrated in Figure 1. The dimensions of the existing cross-sectional area of beams and columns are shown in Table 1.

\subsubsection{Details}

The amounts of longitudinal and transverse reinforcement and their detailing for columns and beams are illustrated in Fig. 2 and Fig. 3. The percentage of total longitudinal reinforcement in beams is fitting with that required by the RPA99 / V2003 [1].

\subsubsection{Materials}

In order to assess the current mechanical properties of concrete, a non-destructive testing has been performed. The measured compressive stress $\mathrm{f}_{\mathrm{ck}}$ is $16 \mathrm{MPa}$, while the computed value of $f_{\text {ck }}$ is $25 \mathrm{MPa}$. Moreover, steel offers good resistance to tensile stresses with a value of $f_{\text {cy }}$ equal to $400 \mathrm{MPa}$.
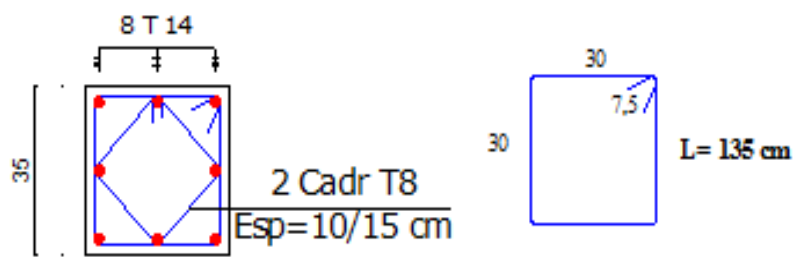

35

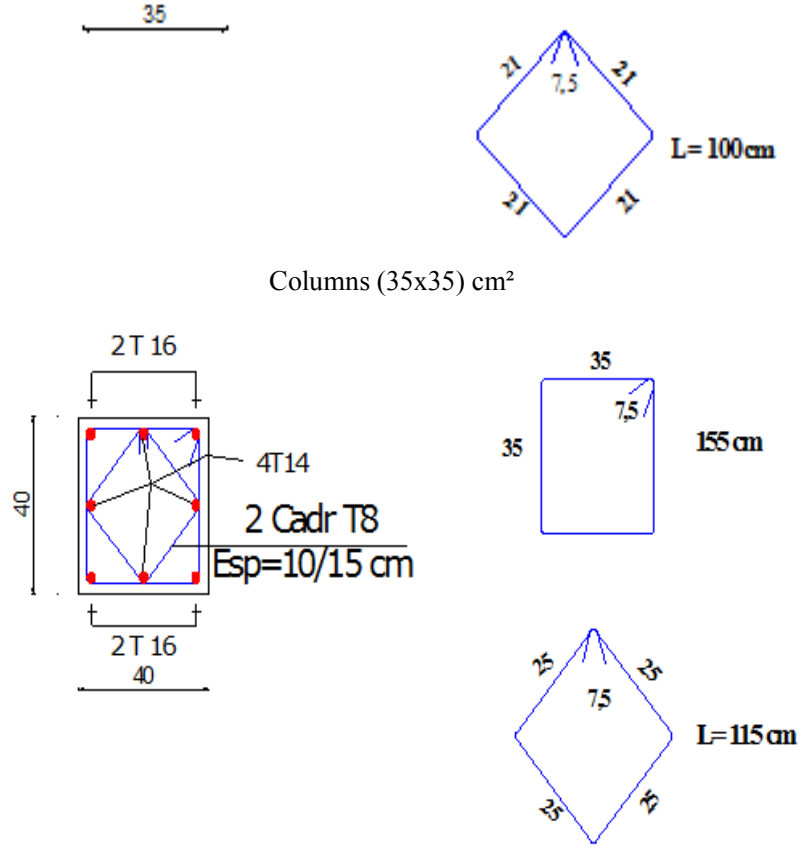

Columns (40x40) $\mathrm{cm}^{2}$

Figure 2. Detailing of columns

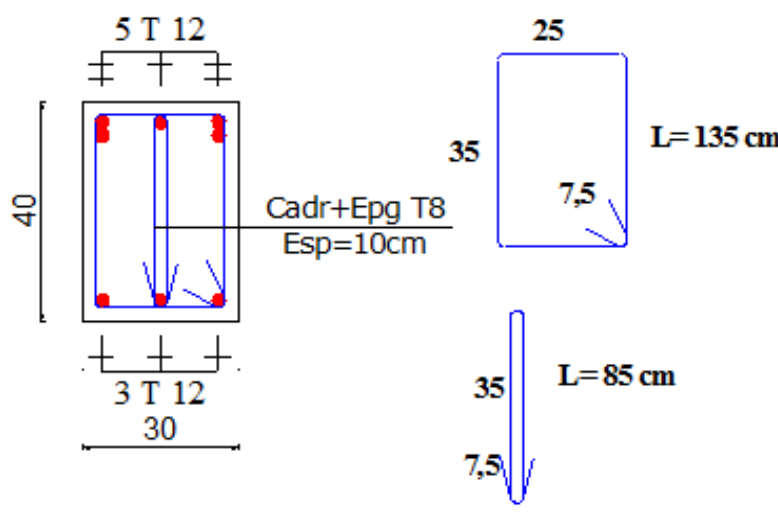

At end

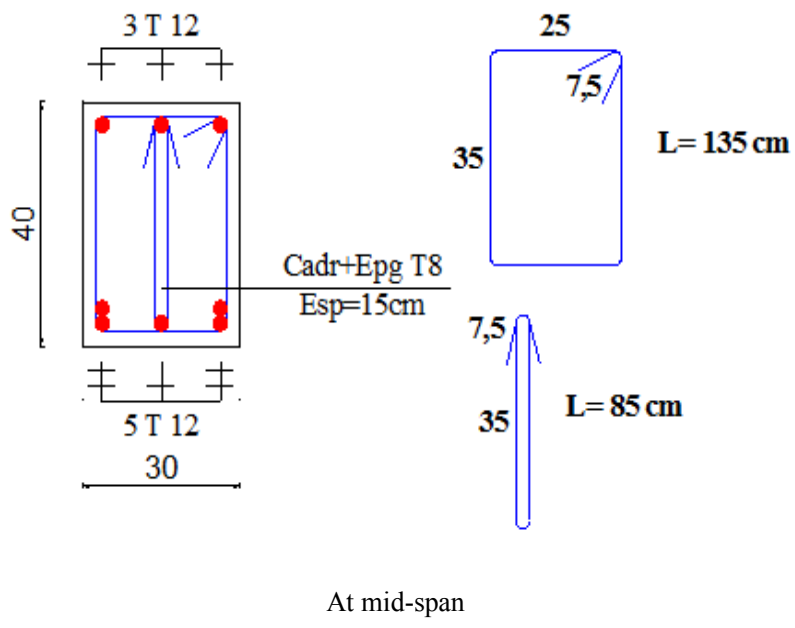

(A) Primary beams

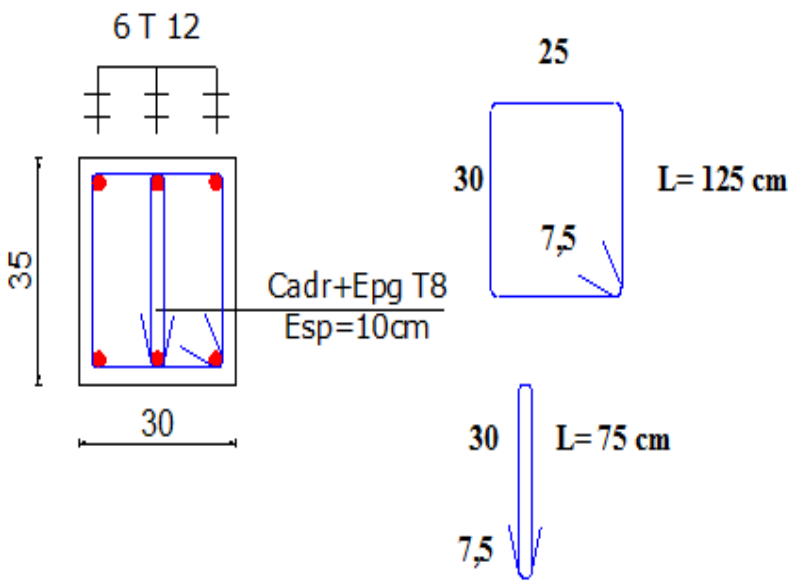

At end 


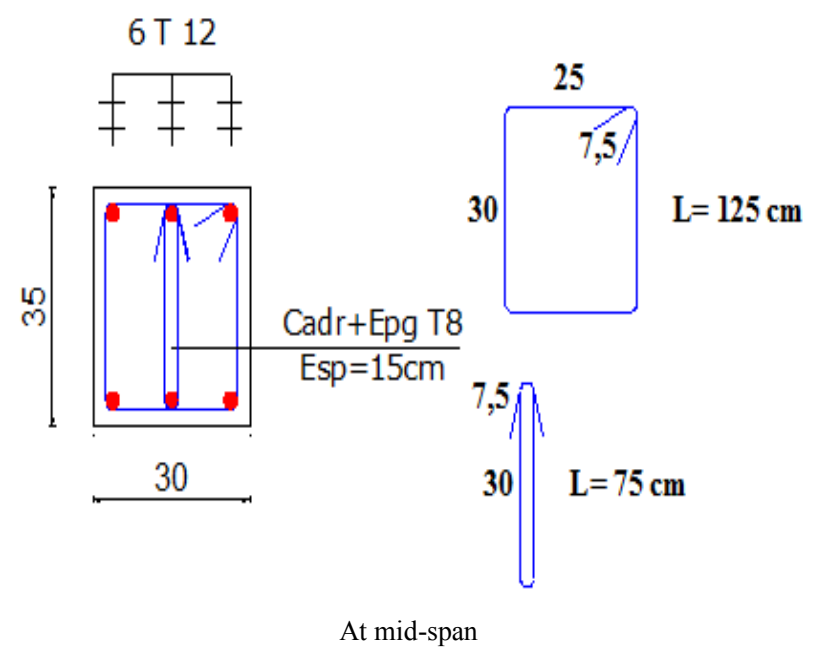

(B) Secondary beams

Figure 3. Detailing of beams

\section{Evaluation of Vulnerability of Building}

The evaluation of the seismic vulnerability of the building is performed using the linear dynamic method with SAP2000 software. After modeling of the structure, the natural periods of vibration, and participation of the masses as well as the Eigen modes are estimated. Then, the seismic force is determined at the base using the equivalent static method. Finally, the inter-storey drifts then the lateral displacement of the whole structure are checked.

\subsection{Building Modeling}

The modeling shown in Fig. 4 by SAP2000 software enables to study the elastic structure. Hence, the model considers the selected members of the structure according to the following concept:

- The Beams and columns will be modeled by bars "FRAME";

- The Floors have infinite stiffness in their plane; this is done by assigning an element "DIAPHRAGME";

- The Mass of each floor is concentrated at its gravity center.

- The load path due to each structure member allows the weight evaluation of each floor as illustrated in fig. 5. The total weight of the structure was found equal to $44619.65 \mathrm{KN}$.

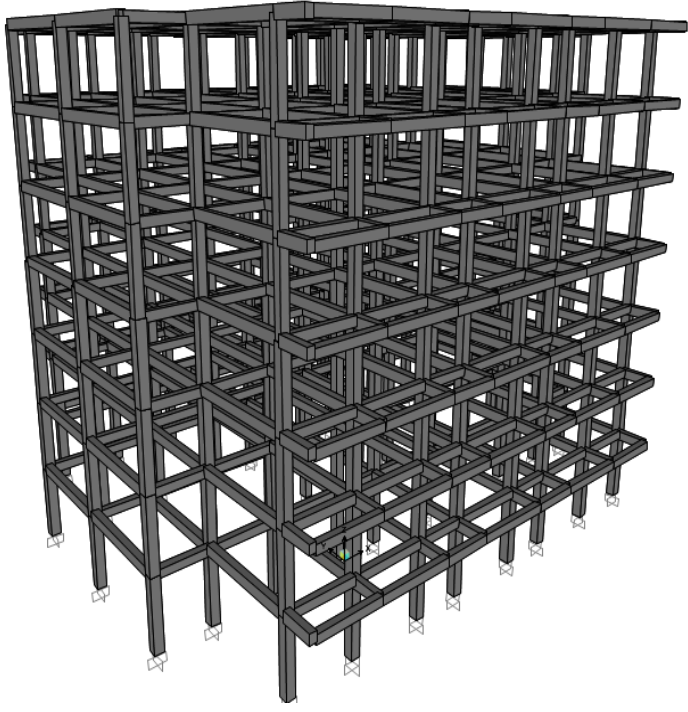

Figure 4. Building Modeling

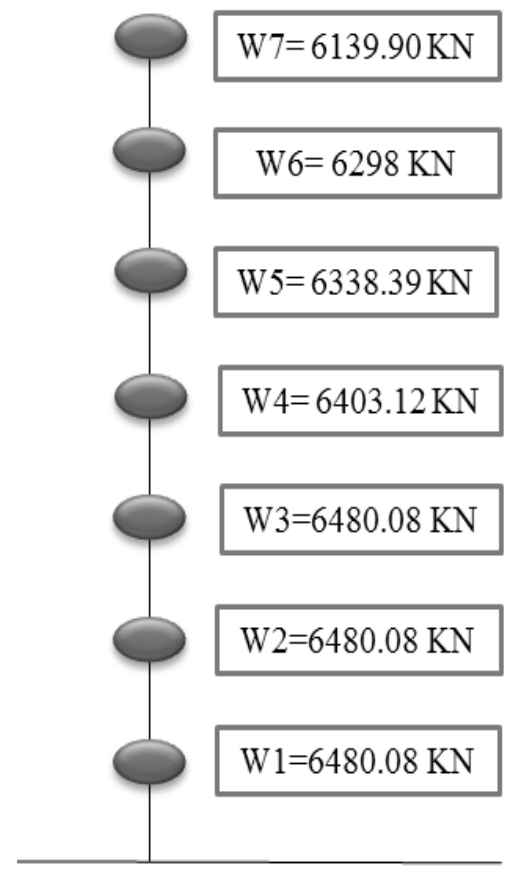

Figure 5. Weight of each floor

\subsection{Natural Periods}

In this section the natural vibration periods are determined, as well as the modal mass participation and mode, using the SAP2000 software. For the three main directions of the structure the values of fundamental periods are: 


$$
\begin{aligned}
& \mathrm{T} 1=1.31 \mathrm{sec} \text { for the } 1 \mathrm{st} \text { period } \\
& \mathrm{T} 2=1.24 \mathrm{sec} \text { for the } 2 \mathrm{nd} \text { period } \\
& \mathrm{T} 3=1.22 \mathrm{sec} \text { for the } 3 \mathrm{rd} \text { period }
\end{aligned}
$$

The first two modes are translational modes (which is acceptable), and the third mode is a torsional mode. These periods shall not exceed the fundamental period of the structure TRPA increased by $30 \%$, which is established from the empirical formula of RPA99 / V2003 [1]. 0.55 sec is the estimated value of the TRPA. The results obtained show that the actual periods in both directions are far beyond 1.3TRPA. This is due to the flexibility of the construction which confirms its vulnerability.

\subsection{Determination of the Seismic Force}

The seismic force evaluation determined by the SAP 2000 software were found equal to $2627,904 \mathrm{kN}$ in the $\mathrm{x}$ direction and $2648,089 \mathrm{KN}$ in the $\mathrm{y}$ direction. These forces shall not be less than $80 \%$ of the prescribed seismic forces VRPA determined by the equivalent static method. The values of these forces are $4747.79 \mathrm{KN}$ in the $\mathrm{x}$ direction, and 4945.61 in the y direction. Comparing these forces in each direction with the actual seismic forces shows that they are beneath the values required by RPA99 / V2003. The gap exceeds by $30 \%$ of that obtained by the empirical formula. This confirms the vulnerability of the structure as it has been proved in the verification of the fundamental period. This also shows that the original design seismic force in zone I was very low according to former RPA 88 [12] regulation.

According to the study of vulnerability by the linear dynamic analysis, the studied construction showed a glaring deficiency in the period and the design base shear. This requires seismic retrofit of the construction is essential to reduce its vulnerability.

\section{Study of the Rehabilitation of the Building}

Decision should be focused on how to intervene based on the conclusion of the condition assessment of structural vulnerability. The type of remedial intervention, its technique, scale and urgency, must refer to the report from condition assessment which provides information of the actual condition of the building [10].

\subsection{Technical Criteria}

It should be taken into account the following technical criteria [10]:

a. repair of all identified structural defects in appropriate manner to ensure safety of the structure;

b. In case of highly vertical mass or stiffness irregularity in the existing building, structural regularity should be improved as much as possible, both in elevation and in plan;

c. The required characteristics of regularity and resistance can be achieved by either modification of the strength and/or stiffness of an appropriate number of existing components, or by the introduction of new structural elements;

d. Increase in the local ductility supply should be affected where required;

e. The increase in strength after the intervention should not reduce the available global ductility;

\subsection{Type of intervention}

An intervention may be selected from the following indicative options [10]:

a. Local or overall modification of damaged or undamaged elements (repair, strengthening or full replacement), considering the stiffness, strength and/or ductility of these elements;

b. Addition of new structural elements (e.g. bracings or infill walls; steel, timber or reinforced concrete belts in masonry construction; etc.);

c. Modification of the structural system (removal of some structural joints and vulnerable elements; widening of joints; modification into more regular and/or more ductile arrangements);

d. Addition of a new structural system to sustain some or all of the entire seismic action;

e. Possible conversion of existing non-structural elements into structural elements;

f. Introduction of passive protection devices through either dissipative bracing or base isolation;

g. Mass reduction;

h. Restriction or alteration of the building usage;

i. Partial demolition;

One or a combination of several options of retrofit strategies can be chosen. It should, in any case take into account the effect of changes in structure on the foundation.

\subsection{Proposed Solution}

In order to increase the resistance capacity and ductility of the structure, the limited funding has restrained the strengthening of the resisting frames of building to the addition of new shear walls in the original plan of the building as shown in Fig. 1. Concrete walls should be integrated at the periphery of the building, so to preserve the integrity of the interior of the building and conserve a reasonable regularity in plan and elevation. The compressive strength used for shear walls for is equal to 25 $\mathrm{MPa}$.

The specific concern is to ensure that adjustments brought to the building configurations can satisfactorily carry lateral loads suitably and in harmony with the 
existing structure. The proposed solution is illustrated in fig. 6 .

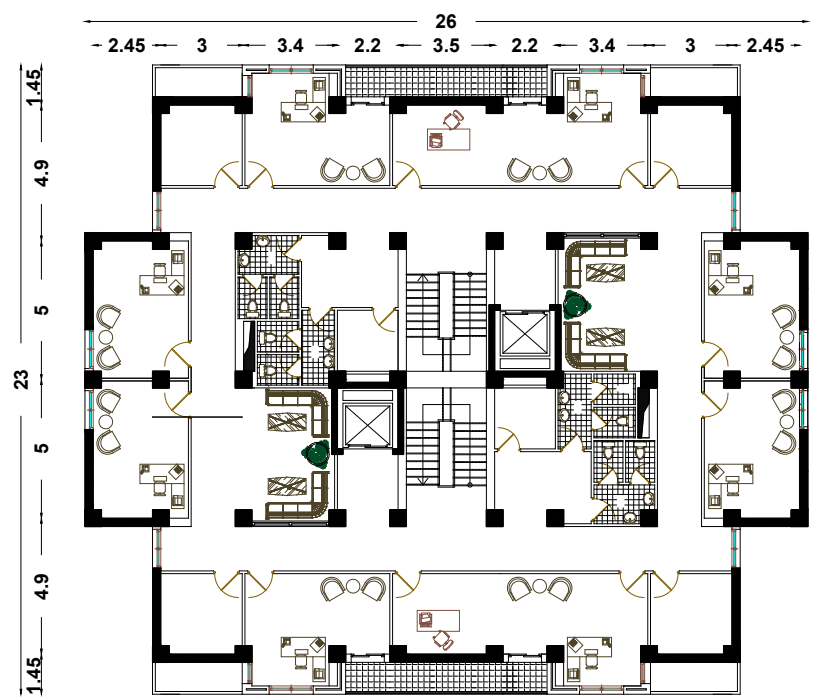

Figure 6. Plan of strengthening building

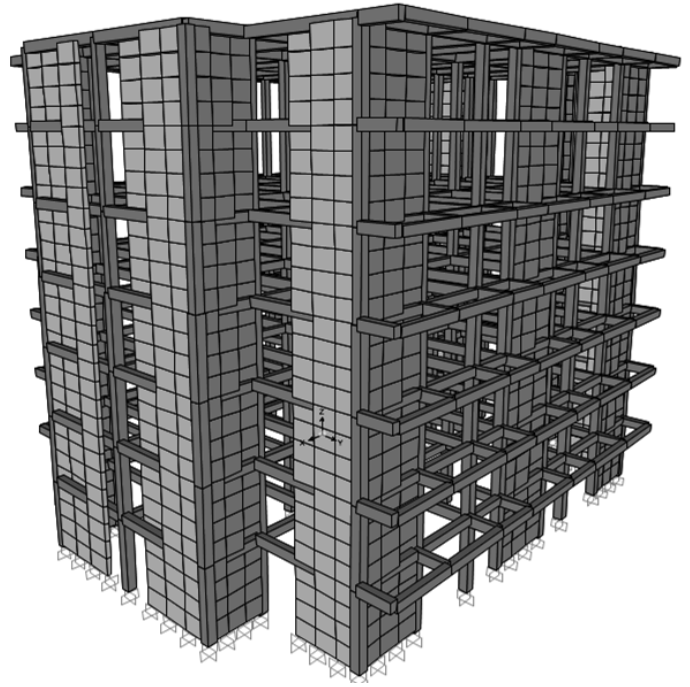

Figure 7. Modeling of strengthening building

\subsection{Dynamic Study of the Building with the Proposed Solution}

\subsubsection{Modeling of the structure}

The new shear walls are already integrated and arranged in accordance to the recommendation of the Algerian Earthquake Regulations (RPA 99 / V2003 [1] concerning the stability of the structure (Figure 7). Non-structural elements are considered as dead loads only.

\subsubsection{Checking dynamic characteristics of the building}

The results obtained using the SAP2000 software have given specific periods $\mathrm{T}_{\mathrm{X}}=0.52 \mathrm{sec}$ and $\mathrm{T}_{\mathrm{Y}}=0.42 \mathrm{sec}$ for the new structure in $\mathrm{x}$ direction, and $\mathrm{y}$ direction respectively, While the estimated value of the fundamental period TRPA is $0.46 \mathrm{sec}$. These results show that the actual periods $\mathrm{T}_{\mathrm{X}}$ and $\mathrm{T}_{\mathrm{Y}}$ are less than the factored fundamental period by $30 \%$, according to the RPA99 / V2003 code $\left(\mathrm{T}_{\mathrm{X}}\right.$ and $\mathrm{T}_{\mathrm{Y}}<1.3 \mathrm{TRPA}=0.56 \mathrm{sec}$ ). This shows that the shear walls placement is improving the resisting capability of the building.

Determined seismic resulting forces of the retrofitted structure are $3420 \mathrm{KN}$ and $3603 \mathrm{KN}$ in $\mathrm{X}$ and $\mathrm{Y}$ directions respectively. These forces must not be less than $80 \%$ of the prescribed seismic forces $V_{\text {RPA }}$ determined by the equivalent static method. The values of these force are the same in both directions $\left(\mathrm{V}_{\mathrm{XRPA}}\right.$ and $\left.\mathrm{V}_{\mathrm{YRPA}}\right)$ are equal to $3772 \mathrm{KN}$. Comparing the forces in each direction shows that the actual resisting seismic forces are greater than those required by RPA99/V2003. This shows that the undertaken structural interventions aimed at stiffening the building were adequate.

\section{Performance of the Strengthening Studied Building}

The results obtained by push-over (non-linear static analysis) analysis elucidated as capacity curves using SAP 2000 software enabled a comparison of the nonlinear behavior between the strengthened structure and the old one.

\subsection{Shear Force}

Fig. 8A highlights a confrontation between the old building capacity curves before and after strengthening the structure by adding reinforced concrete bracing walls in both directions. This figure clearly shows the importance of the adopted strengthening in terms of base shear, where the strengthened structure capacity curve corresponding to that modification is far more exceeding the one of the non-strengthened structure. In the original building, the value of the base shear is $2783.031 \mathrm{KN}$ which represents less than $65 \%$ of the value found using the equivalent static method in the $\mathrm{x}$ direction $\left(\mathrm{V}_{\mathrm{X}}=3675,054 \mathrm{KN}\right)$. This value increases to $11020.129 \mathrm{KN}$ for the strengthened structure which is about four fold increase in computed force for the original building, and more than three times the strength value when using the equivalent static method for the same direction $\left(V_{X}=3772,27 \mathrm{KN}\right)$. The same observation is noticed for improving the behavior of the structure for the $\mathrm{y}$ direction in Fig. 8B. Therefore, it can be noticed that the overall resistance capacity of the strengthened structure is improved more than three times compared to the original structure.

\subsection{Displacement}

From Fig. 8A, in terms of roof displacement, the capacity curve of the original structure shows that the final 
displacement reaches a corresponding value of $0.24 \mathrm{~m}$, which is enhanced to $0.34 \mathrm{~m}$ for the strengthened structure, which represents approximately a $15 \%$ increase. For the y direction (Figure 8B), the displacement reached a value of $0.29 \mathrm{~m}$ for the non-strengthened structure, which is increased to $0.33 \mathrm{~m}$ with a rate of $10 \%$ for the strengthened structure. Accordingly, the structure deformation capacity is not greatly improved is still in a range that does not exceed 10 to $15 \%$.

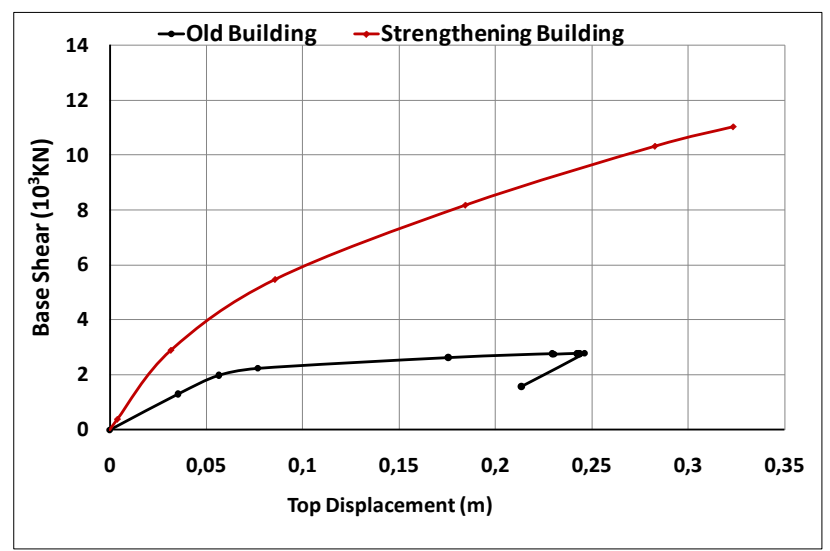

(A) Capacity curves in $\mathrm{x}$ direction

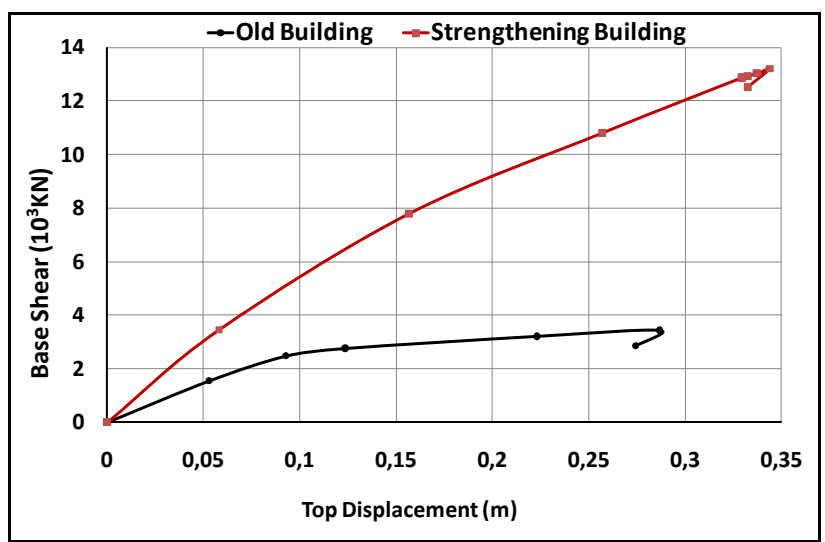

(B) Capacity curves in y direction

Figure 8. Comparison between the capacity curves before and after strengthening the structure

\subsection{The Structure Performance Point}

The performance point enables to make several considerations on the structure behavior according to the earthquake from the integration of regulatory spectrum response corresponding to the current seismic zone on the capacity curve of the structure [11]. In this case, the junction is almost at the limit of elastic behavior of the structure in both directions as shown in Fig. 9 for the old structure, and Fig. 10 for the strengthened one. Table 2 shows a comparison between the performance point values obtained in terms of shear, displacement and damping $\varepsilon_{\text {eff }}$ for the structure before and after strengthening. According to this table, we observe that the values for the original structure are lower than the ultimate values obtained previously which furthermore confirms that the structure is vulnerable.

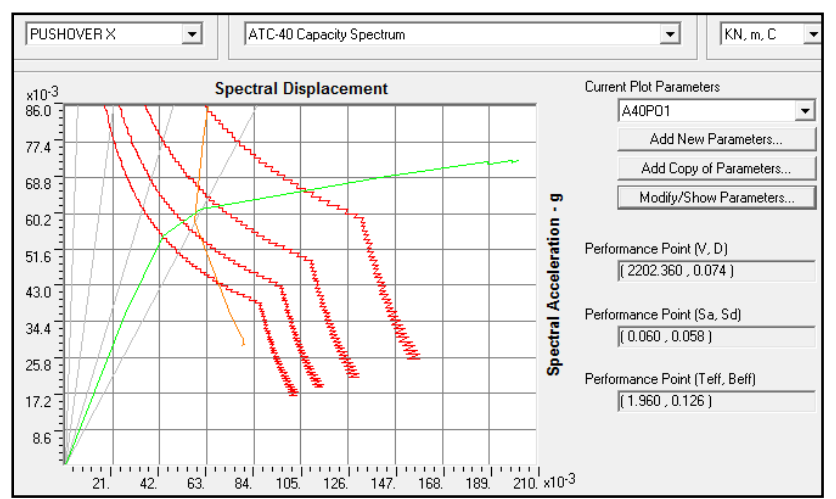

(A) $\mathrm{X}$ direction

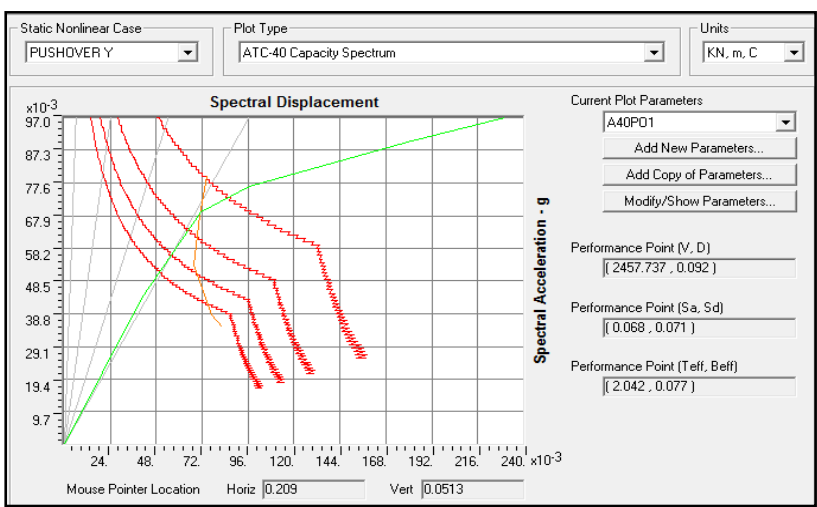

(B) Y direction

Figure 9. Performance point for the structure before strengthening

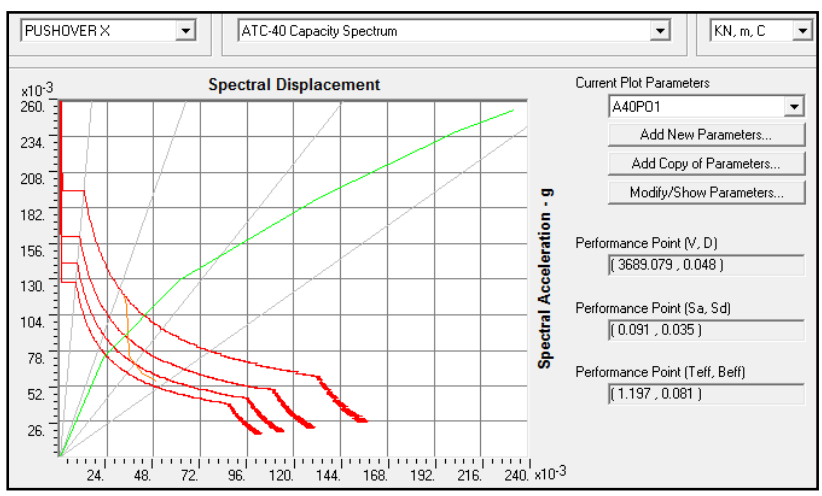

(A) $\mathrm{X}$ direction

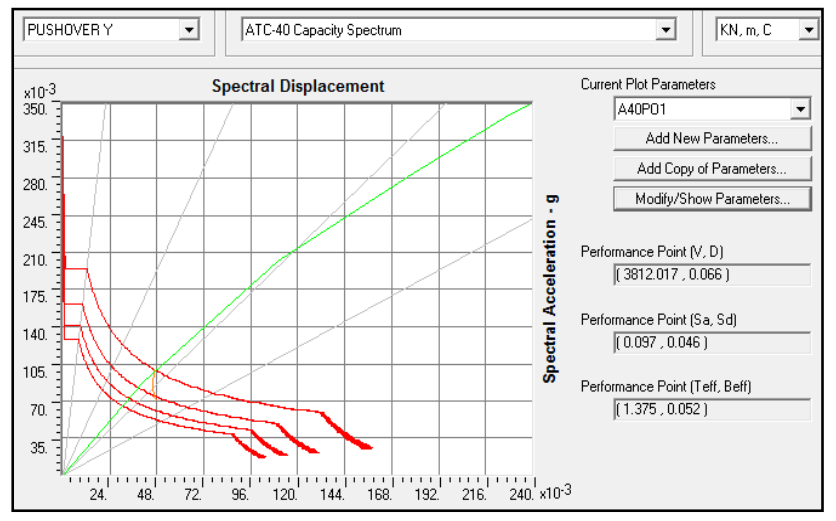

(B) Y direction

Figure 10. Performance point for the structure after strengthening 
Table 2. Comparison between the performance point values for the structure before and after strengthening

\begin{tabular}{|c|c|c|c|}
\hline & & Before strengthening & After strengthening \\
\hline \multirow{3}{*}{ X direction } & Shear force V $(\mathrm{KN})$ & 2202,36 & 3689,08 \\
\cline { 2 - 4 } & Damping $\varepsilon$ eff & 0,126 & 0,081 \\
\hline \multirow{2}{*}{ Y direction } & Shear force V $(\mathrm{KN})$ & 2456,74 & 3812,02 \\
\cline { 2 - 4 } & Damping $\varepsilon$ eff & 0,077 & 0,052 \\
\hline
\end{tabular}

However, the values obtained for the retrofitted structure is well above that found previously for base shear force and control displacement. As a consequence, the performance point values of the strengthened structure show a clear improvement in the resistance and damping that is greater than the initial values of the original structure by $80 \%$.

\section{Conclusions}

The study of vulnerability using the linear dynamic analysis, studied building showed a great deficiency into the dynamic characteristics, namely its natural period and the seismic base shear, which requires rehabilitation. A brief presentation of the rehabilitation method of Eurocode 8-3 [10] was exposed. An adopted strengthening solution of construction was proposed. The highlighting of the performance of the proposed solution for the strengthening is performed using a non-linear static analysis.

The study of the performance of the building before and after strengthening using push-over analysis enables to draw the following conclusions:

- The overall resisting capacity of the strengthened structure is improved by more than three times compared to the old structure.

- The structure deformation capacity is not greatly enhanced, but remains within a range that does not exceed 10 to $15 \%$.

- The performance point values after of the strengthened structure show a clear improvement in the resistance and damping that exceed $80 \%$ of the initial values of the original structure.

\section{REFERENCES}

[1] RPA-99/ 2003, 2004, Règles parasismiques Algériennes 1999 - Version 2003. DTR-BC 248 - Centre National de
Recherche Appliquée en Génie sismique (CGS), Alger.

[2] Penelis G.G., Kappos A.J, Earthquake resistant concrete structures, Edition E \& FN SPON, 1997.

[3] Sarno L. Di and Manfredi G., 2009, Seismic assessment of a $\mathrm{RC}$ school building retrofitted with innovative braces, Concrete Repair, Rehabilitation and Retrofitting II Alexander et al (eds), 2009 Taylor \& Francis Group, London, pp. 1149-1155.

[4] Hassaballa A. E., Ismaeil M. A., Fathelrahman M. A., 2014, Seismic Evaluation and Retrofitting of Existing Hospital Building in the Sudan, Open Journal of Civil Engineering, 4, 159-172.

[5] Ahmed M., Nazar S., Islam S., Khan R. A., 2014, Seismic Performance and Strengthening Study of Concrete Frame Structure Building, Journal of Multidisciplinary Engineering Science and Technology (JMEST), Vol. 1 (5), pp. 478 - 482

[6] DAVIDOVICI Victor, réhabilitation des hôpitaux existants, 2007.

[7] DAVIDOVICI Victor, renforcement par mur en béton armé, 2006.

[8] Recommandations techniques pour la réparation et le renforcement des ouvrages, Algérie.

[9] Catalogue des méthodes de réparation et de renforcement des ouvrages - CGS- 1992, Algérie.

[10] EN 1998-3:2005 E, Eurocode 8: Design of structures for earthquake resistance Part 3: Assessment and retrofitting of buildings, European Committee for Standardization, Brussels.

[11] EN 1998-1:2004 E, Eurocode 8: Design of structures for earthquake resistance Part 1: General rules, seismic actions and rules for buildings, European Committee for Standardization, Brussels.

[12] RPA-88, Règles Parasismiques Algériennes, Centre National de Research Appliquee en Genie Parasismique (CGS), 1989. DTR, Algiers, (in French).

[13] CCBA 68, Règles techniques de conception et de calcul des ouvrages et constructions en béton armé, PARIS 1968 (in French). 